\title{
NO EMBARALHAMENTO COM EXU
}

\author{
Luisa Mesquita Damasceno ${ }^{1}$
}

RESUMO: Como dialogar com um sem número de exu (s)? Exu modifica-se a depender de quem narra suas histórias. Não se apresenta de forma única, é aberto a várias versões. Se faz nas singularidades dos contextos em que se apresenta. É rizomático: composição de matérias heterogêneas, atravessado por muitas linhas de intensidade. Brinco com ele aqui, a partir de um pensamento andarilho, dando lugar a múltiplas verdades que não se coadunam com o uno e o idêntico a si mesmo. Navego com exu no embaralhamento dessas verdades, na pluralidade das vozes em que o real é inesgotável.

PALAVRAS-CHAVE: exu; religiões afro-brasileiras; multiplicidades.

\begin{abstract}
ABRIR VELAS
Singrando com cuidado e gingando com a maré, me lanço nesse emaranhado de muitas possibilidades que é navegar em/com exu. O cavaleiro andante e menino reinador como disse certa vez Jorge Amado. E nada mais propício do que iniciar essa tessitura com o padê². O encontro. Exu é o guardião dos entrecruzamentos, dos pontos de contato, das relações. É a partir do encontro que surgem as mudanças, o movimento. É dele também o papel de zelar e prover o movimento. Ele é o próprio movimento, dizem alguns.

\footnotetext{
${ }^{1}$ luisamesqd@gmail.com Mestranda em Ciências Sociais na Universidade Federal do Recôncavo da Bahia
}

${ }^{2}$ Em consonância com o dicionário de Cultos Afro-Brasileiros de Olga GudolleCacciatore (1977), padê é o ritual propiciatório, com oferenda a exu, realizado antes do início de toda cerimônia pública ou privada dos cultos afro-brasileiros. Certa vez, ao perguntar à Iyalorixá do terreiro IlèAsè Ala OjúMejiOfáOtún, localizado em São José da Lapa - MG sobre o significado do padê, ela me forneceu a seguinte resposta: "É informar exu. É sair do movimento profano para acessar o divino. É como bater na sua porta, informar que tem visita. Para informar que tem visita tem uma campainha, não tem? Então. Opadê tem o propósito de dar satisfação a esse senhor que tem visita. Que terá um encontro".
\end{abstract}


Compreendendo que todo encontro se faz a partir de uma relação sempre singular, convoco Deleuze e Guattari para me auxiliarem a pensar sobre/com o candomblé e por consequência, a dialogar com exu.

O candomblé, como já apontaram Bastide (1989); Goldman (2005) e Anjos (2008), está mais apoiado sobre multiplicidades do que sobre estados do ser concebido como fundamentalmente unitário. A multiplicidade que se faz presente no candomblé se contrapõe às noções de unidade-continuidade estabelecida pela visão integradora e dualista da razão ocidental e do seu "princípio de identidade e da não-contradição". (BASTIDE, 1989, apud ANJOS, 2008, p.81). No universo do candomblé precede-se mais por um pensamento feitos de linhas, devires e multiplicidades onde cada multiplicidade já é composta de termos heterogêneos em simbiose, como pode ser percebido nos orixás, nos filhos-de-santo e em tudo mais que participa desse universo.

Os orixás, como já apontou Goldman (2005) podem ser lidos como modulações do axé3, em que cada orixá é uma modulação específica de axé, assim como os humanos e as coisas do mundo: as pedras, as plantas, os animais, as cores, sabores, cheiros, tudo isso "pertence a diferentes orixás na medida em que com eles compartilham dessa essência simultaneamente geral e individualizada" (GOLDMAN, 2005, p.14). Além disso, cada orixá apresenta-se em uma quantidade variável de "qualidades"4. E, ainda, pode-se falar do orixá individual de determinado filho-de-santo, que inclusive pode ser o mesmo orixá, com a mesma qualidade de um outro filho-de-santo e mesmo assim serem orixás diferentes, com intensidades distintas. Assim, tem-se os orixás gerais, que têm um certo

\footnotetext{
${ }^{3}$ De acordo com Juana Elbein dos Santos (1986), o conteúdo mais precioso do terreiro é o axé. A força que assegura a existência dinâmica, que permite o acontecer e o devir. É importante salientar que o axé é propulsionado por exu. Além disso, o axé é mantido e realimentado permanentemente no "terreiro". Por meio da atividade ritual, o axé é liberado, canalizado, fixado temporariamente e transmitido a todos os seres e objetos, consagrando-os.

${ }^{4}$ Qualidade refere-se aos vários nomes que um mesmo orixá é conhecido, referindo-se a um determinado aspecto mítico da divindade, a uma sua função específica no patronato do mundo, a um acidente geográfico a que é associado, etc. Mas também é muito conhecido nos terreiros que, a depender da "qualidade" de um determinado orixá, pode-se dizer que ele é quase um outro orixá por conta de suas características.
} 
nível de realidade, presente nos mitos e, na intimidade de cada terreiro e de cada filho-de-santo, os orixás se singularizam.

O encontro das diferenças na religiosidade afro-brasileira é rizomática, disse certa vez Anjos (2008). O rizoma contraria-se ao pensamento ocidental, arborescente, que se caracteriza por pensar a partir da dualidade e da compartimentalização, em que o tronco é a referência principal, que guia todos os outros segmentos da árvore. O rizoma é horizontal, "estranho a qualquer ideia de eixo genético ou de estrutura profunda" (DELEUZE; GUATTARI, 1995, p.21). Rizoma é uma raíz que tem um crescimento diferenciado, polimorfo, que cresce horizontalmente e não tem uma direção clara e definida. "No coração de uma árvore, no oco de uma raíz ou na axila de um galho, um novo rizoma pode se formar. Ou então é um elemento microscópico da árvore raiz, uma radícula, que incita a produção de um rizoma”. (DELEUZE; GUATTARI, 1995, p.24). O rizoma não começa nem conclui, se faz na encruzilhada, qualquer ponto se conecta com outro.

É na encruzilhada que se tem o "ponto de encontro de diferentes caminhos que não se fundem numa unidade, mas seguem como pluralidades" (ANJOS, 2008, p.80) no universo afro-brasileiro que, em lugar de dissolver as diferenças, conecta o diferente ao diferente, deixando as diferenças subsistirem enquanto tal. Me situo nessa encruzilhada. No palco do mundo 5 , para brincar com exu a partir de um pensamento andarilho e um tanto confuso.

Como dialogar com um sem número de exu (s)? Arredio, desaparece tão logo a tentativa de defini-lo lhe espreite. Como disse Babá Egbe ${ }^{6}$ : Exu gosta de brincar! Nos mostra que nada é o que parece ser. Tão logo, exu também pode não ser o que parece ser.Exu é rizomático: se esconde, confunde, sabota, corta caminho, inventa novos trajetos, e está sempre aberto às experimentações. A

\footnotetext{
${ }^{5}$ Tomo de empréstimo a ideia da encruzilhada como palco do mundo da fala de Aderbal Moreira, Ashogun do Ilê Axé OmiOjuArô presente no documentário A Boca do Mundo - Exu no Candomblé, que pode ser visto em: https://www.youtube.com/watch?v=Ja28zM8_J3w

${ }^{6} \mathrm{~A}$ fala de Babá Egbese encontra no documentário A Boca do Mundo - Exu no Candomblé, que pode ser visto em: https://www.youtube.com/watch?v=Ja28zM8_J3w
} 
multiplicidade é sua principal característica, nunca é o idêntico a si mesmo, se modifica no caminho, são vários, se faz nos devires.O devir permite o abandono dos territórios repetidos, dos caminhos já traçados.

O devir em si é multiplicidade e heterogeneidade, é linha de fuga, é um vir a ser

Devir é, a partir das formas que se tem, do sujeito que se é, dos órgãos que se possui ou das funções que se preenche, extrair partículas, entre as quais instauramos relações de movimento e repouso, de velocidade e lentidão, as mais próximas daquilo que estamos em vias de devir, e através das quais devimos. É nesse sentido que o devir é o processo do desejo" (DELEUZE; GUATTARI, 1980 apud GOLDMAN, 2005, p.18/19).

O devir exu-cavalo-de-santo é quando o humano entra em um agenciamento com exu, quando ocorre uma aliança entre os dois onde se estabelecem trocas “intensivas”. Ou seja, o cavalo-de-santo se avizinha das potências de exu, que assegura a desterritorialização do cavalo-de-santo enquanto humano apenas e a reterritorialização de exu. Não há imitação nem semelhança, mas, sim o encontro exu-cavalo-de-santo. Ou, nos rastros de Goldman (2005), o devir exu-cavalo-de-santo pode ser entendido como o movimento por meio do qual um sujeito sai de sua própria condição (humana) por meio de uma relação de afetos que consegue estabelecer com uma condição outra (divina). Assim, “o devir é o que nos arranca não apenas de nós mesmos, mas de toda identidade substancial possível”. (GOLDMAN, 2005, p.19). O devir exu-cavalo-de-santo explode a unidade do sujeito, fazendo de seu corpo um espaço em que exu pode navegar.

\section{ÁGUAS LIVRES7}

\footnotetext{
${ }^{7}$ No linguajar dos navegadores, daqueles que conhecem o mar, o termo águas livres diz sobre as águas que não são territoriais ou jurisdicionais, isto é, não são subordinadas ao domínio ou à jurisdição de qualquer nação, sendo, portanto, as águas do alto-mar ou pleno oceano, os quais não pertence à ninguém. Como Exu. A definição de "águas livres” pode ser encontrada em: http://peska.com.br/novopeska/dicassobre-pesca/peixes/340-dicionario-de-navegacao
} 
Imergindo no pensamento de Paul Gilroy (2001), que compreende o mar e a vida marítima como chaves de leitura para o diálogo com a trans-cultura negra e sua criatividade inter-cultural, também os compreendo como chaves de leitura possíveis para o diálogo com exu. O mar e exu movimentam-se e misturam-se a todo instante, em um insistente ir e vir possibilitando os mais variados encontros. E é a partir, especificamente do atlântico e de seus cruzamentos entre África, Europa e América que exu se apresenta em solo brasileiro.

Viajantes e missionários católicos europeus que cruzaram o atlântico em direção à África, durante o século XVIII, estiveram em território Fon e Yorubá e, de acordo com Silva (2012), escrevem os primeiros registros sobre exu. Nessas narrativas, impregnadas pelo olhar etnocêntrico cristão, o caráter fálico da divindade tornou-se sinônimo de uma sexualidade depravada, o que, somado a outros aspectos tais como sua porção brincalhona contada nos mitos, ocasionou sua associação com o diabo cristão. Seguindo essa rota, Nina Rodrigues (1935), ao pesquisar o universo do candomblé na Bahia, o coloca como a representação do mal em oposição ao bem, que seria representado nessa perspectiva, por Oxalá. Arthur Ramos, seguidor de Nina Rodrigues, declarou que exu era uma "poderosa entidade dotada de poderes maléficos especiais" (RAMOS, 1979, p.63).

Na contramão de uma identidade unívoca sobre exu, discursos como os de Pierre Verger (2012), Stefania Capone (2004) e Juana Elbein dos Santos (1986), ao se debruçarem sobre as características dessa divindade ainda em África, ressaltam características que não permitem a correspondência imediata entre o orixá e o diabo cristão, como fizeram alguns.

Na perspectiva de Juana Elbein dos Santos (1986), exu se impõe como imprescindível para a compreensão da toda a cosmogonia e liturgia yorubana, que assim como Olodumarê, não pode ser isolado ou classificado em nenhuma categoria. É considerado como um princípio, responsável por transportar o axé de e para tudo o que existe. Nessa abordagem, ele é o princípio dinâmico da existência e de expansão de tudo, sem ele todos os elementos do sistema e seu devir ficariam imobilizados e a vida não se desenvolveria. 
Já nas narrativas de Verger (2012), as principais características de exuque são ressaltadas, são suas porções mensageira, protetora e trapaçeira. $\mathrm{O}$ autor discorre sobre a presença de exu enquanto guardião dos templos, das casas e das cidades, bem como apresentando-se como a cólera dos orixás e das pessoas, já que possui um caráter suscetível, astucioso e vaidoso. Para Verger, exu não é nem completamente bom, nem completamente mau, é o fiel mensageiro daqueles que o enviam e que lhe fazem oferendas.

Ao tratar sobre exu ainda em África, Capone (2004) ressalta que ele é o grande comunicador, aquele que interliga o mundo dos deuses com o dos homens. Quem restaura a ordem do mundo, mas, ao mesmo tempo, desfaz as abordagens conformistas do universo, ao introduzir desordem e a possibilidade de mudança.

Ao cruzar o atlântico e se fazer presente no Brasil, exu transforma-se e recebe mais algumas características, que em decorrência da escravidão e da conversão obrigatória ao catolicismo, o fez ser comparado no sincretismo brasileiro ora com Santo Antônio, São Gabriel, São Benedito e São Pedro (prevalecendo seu aspecto de deus mensageiro) ora com o diabo cristão e os espíritos dos mortos (prevalecendo seu caráter trickster ${ }^{8}$ ) (SILVA, 2012). Além da presença do catolicismo que conferiu à exu algumas faces a mais, a umbanda também lhe conferiu mais uma porção de características. Para Prandi (2001), a expansão do candomblé por todo país se fez a partir de uma base umbandista, que se formou antes da transformação do candomblé em religião aberta a todos. Assim, o autor constata que a adesão ao candomblé por parte de alguns adeptos, muitas vezes antes umbandistas, não tem significado o compromisso de abandonarcompletamente concepções e entidades da umbanda. Ao contrário, há um repertório umbandista cada vez mais agregado ao candomblé, a ponto de se

\footnotetext{
${ }^{8}$ De acordo com Capone em "A busca da África no Candomblé - Tradição e Poder no Brasil”, Mac Lins CottRicketts define a figura de trickster assim: $\mathrm{O}$ criador da Terra e/ou [...] aquele que transforma $\mathrm{o}$ caótico mundo mítico na criação ordenada dos tempos atuais; ele é o exterminador de monstros, o ladrão da luz do dia, do fogo, da água e de tudo que favorece o bem-estar do homem. É também um travesso insultuosamente erótico, insaciavelmente faminto, exageradamente vaidoso, fraudulento, manhoso para com os amigos e inimigos, um incansável viajante pelos cantos do planeta; e um desastrado que, com frequência, é vítima das próprias artimanhas (RICKETTS, 1965 apud CAPONE, 2004, p.53).
} 
falar frequentemente numa modalidade religiosa que seria mais facilmente identificada por um nome capaz de expressar tal hibridismo, como umbandomblé. Dessa forma, em muitos terreiros, exu pode ter uma dupla natureza: ser cultuado, no mesmo local de culto e pelas mesmas pessoas, como o mensageiro mais próximo do orixá africano e como o espírito desencarnado mais próximo dos humanos.

No candomblé, exu é concebido como uma divindade múltipla, assim como ocorre aos demais orixás. No pensamento religioso, exu está relacionado ao número um, que de acordo com Trindade (2006), representa o acréscimo que propicia a continuidade e a dinâmica dos fenômenos. Muitos autores dizem que exu possui vinte e uma qualidades, mas, estando ligado à multiplicidade, esse número em geral é muito maior e varia conforme os terreiros. De acordo com Capone (2004), não se conhece o número ${ }^{9}$ exato dessas formas, mas a quantidade e a diferença entre elas indicam o caráter inapreensível dessa divindade/entidade.

Encarnação da multiplicidade, o orixá exu se multiplica e se divide para acompanhar cada orixá e cada humano. De acordo com Capone (2004), os exus catiços $^{10}$ seriam a individualização da força sagrada do exu orixá geral, uma vez que cada orixá tem seu exu catiço que lhe serve, transportando as oferendas (ebós) do mundo material para o mundo espiritual. "Particularizado na individualidade de cada orixá, exu não contrapõe ou contesta o signo da divindade, muito se infiltra nele" (LODY, 1995, p. 109).

De acordo com Capone (2004), cada ser humano também possui o seu exu pessoal, que está ligado ao seu destino individual e acompanha o iniciado até a morte. Um dos momentos mais importantes do processo de iniciação é a revelação do odù pessoal do noviço (seu destino) e a fabricação de seu exu pessoal. $\mathrm{O}$ exu individual de cada ser humano é o elemento que permitiu seu nascimento, desenvolvimento e multiplicação e, "para que sua existência seja

\footnotetext{
${ }^{9}$ Capone comenta que Idowu (1962:85) fixa em duzentos os diferentes nomes de exu, mas diz que "entre os iorubás o número 200 como seu duplo 400 simboliza a multiplicidade, isto é, uma grande quantidade indeterminada".

${ }^{10}$ Normalmente, na linguagem dos terreiros é assim que se chama os exus "individuais", aqueles que acompanham os orixás e os filhos-de-santo.
} 
cumprida harmoniosamente, deverá restituir, através de oferendas, o asé devorado real ou metaforicamente por seu princípio de existência individualizada" (TRINDADE; COELHO, 2006, p. 26).

Assim, o orixá geral exu tem um certo nível de realidade, muito presente na mitologia, porém, na vida cotidiana dos terreiros e dos filhos-de-santo, exu passa por um processo singularizante no sentido próximo daquele que Deleuze confere ao termo:

O pensamento da diferença trabalha um mundo de individualizações impessoais e de singularidades pré-individuais que é o mundo em que se elaboram os encontros e as ressonâncias, última face de Dioníso... (DELEUZE, 1988 apud ANJOS, 2008, p.85)

Nesse sentido, exu se singulariza constantemente em outras intensidades, se apresentando de formas distintas a depender do evento, já que ele se faz em relação, nas singularidades de cada contexto em que ele se apresenta. As muitas versões sobre exu estão relacionadas às singularidades presentes nas experiências religiosas de cada um, onde se tecem uma teia complexa de agenciamentos entre pessoas, orixás, caboclos, exus e erês. No rastro do pensamento de Rabelo (2008), essas entidades participam ativamente na vida dos adeptos das religiões afrobrasileiras, intervindo na vida do terreiro e na vida particular de cada um, como pode ser percebido quando a IyalorixáNílsia me confidencia a seguinte história ao conversarmos sobre o exu Tranca Ruas que está assentado em seu terreiro: Com Tranca-Rua eu tenho uma belíssima história! Ele foi o primeiro exu a entrar nessa casa. Amo ele como um filho maior que eu tenho. É amor de mãe. Tenho uma relação estreitíssima com ele. Ele zela por minha paz e meu conforto espiritual. Foi ele que me alertou que eu deveria sair da casa do meu Babalorixá no Rio e que eu abriria minha própria casa.

Ou, quando perguntam a Mãe Beata de Iemanján ${ }^{11}$ quem é exu :exu sou eu! Eu, com 78 anos. Nasci em uma encruzilhada, ao meio dia de uma terça-feira. $\mathrm{Na}$

\footnotetext{
${ }^{11}$ A fala de Mãe Beata está contida no documentário A Boca do Mundo - Exu no Candomblé, que pode ser visto em: https://www.youtube.com/watch?v=Ja28zM8_J3w
} 
fome. Minha mãe foi pescar no rio porque não tinha o que comer e, ali dentro, a bolsa estorou e eu comecei a nascer. Ela saiu prendendo as pernas. Fez uma revolução no lugar! Uma senhora africana veio correndo com vários trapos para me aparar. Então, eu sou exu! Exu é meu homem, é meu marido. O que mais me emociona é falar de exu. Exu é meu riso, é minha lágrima, é minha insônia. É tudo o que eu trabalhei. É tudo o que eu adquiri. São as amizades que tenho. Tudo.

A fala de Mãe Beata e a fala da Iyalorixá Nílsia são singulares porque as relações entre elas e exu (s) fazem parte de uma trama permeada pelas memórias de cada uma delas e, por isso, suas narrativas são sempre contextuais. Seguindo Tavares (2013), o conhecimento sobre/com os orixás no candomblé e nas demais religiões afro-brasileiras, passa pelo corpo que experimenta. Trata-se de um saber que pressupõe um sentir. Um sentir-saber que é singular, que leva em conta as idiossincrasias de cada um. Saber que se dá através dos eventos, acontecimentos que atualizam as relações e produzem determinado percurso biográfico. E é nesse sentido prático, criativo, vivido, que se faz presente as relações afetivas ${ }^{12}$ com exu.

Exu modifica-se a depender de quem narra suas histórias. "Multiplicações de versões de um exu que já não cabe mais em si. Em que cada versão não elimina a outra, mas a excede, rasura, arrasta, reelabora e inventa a história de um sujeito multiplicado e fendido". (FERNANDES, 2015, p.141)

Exu é aquele que está em todo lugar. Que vai pra lá e vai pra cá. Que está no morro e no vale. No alto e no baixo, diz o BabalawòAdejimiAderotimiAdefolurin'13. Exu não é o idêntico a si mesmo. Há muitos. Isto posto:

Emoldurar um passado nativo, real, estanque, imerso num tempo sem tempo e sem contexto, consagrar um exu nativo, puro e solene é tão questionável quanto a sua demonização por parte dos missionários e viajantes europeus dos quinhentos. Tanto um quanto o outro, em sua sanha, pretendem engessar exu, demonstrando, em fato, o lugar discursivo e os interesses com os

\footnotetext{
${ }^{12}$ Compreendido aqui não somente como estima e carinho, mas principalmente no sentido trabalhado em "Ser Afetado" de Jeanne Fravet-Saada (1990).

${ }^{13}$ Essa fala está contida no documentário Dança das Cabaças - Exu no Brasil, que pode ser visto em: https://www.youtube.com/watch?v=8Lp61NQib2M
} 
quais se comprometem. Como se pode emoldurar o que é próprio do movimento e afeito às intervenções e mudanças culturais? Há algo mais descabido do que xenofobia de exu contra exu? Um exu - encontrado, fixo, mandão, exu policiando exu, solicitando carteira de validade e crachá de identificação, interditando a multiplicação de exus na Babel de línguas que se encerra, monopolizando o direito (democrático de ir e vir, de fluxo e refluxo) de apenas ele ser exu, violenta todos os outros. (FERNANDES, 2015, p.32)

\section{APORTAR}

Exu pode ser o orixá primordial, que participou da criação do universo, a laterita vermelha, exu Yangui; pode ser o exu da terceira cabaça, exu IgbáKetá; pode ser o do infinito, do caracol, exu Okòtò; pode ser o da felicidade, exu Odàrà; pode ser exu Bárà, dono do corpo. Pode ser também exu -Sete Encruzilhadas; exu-Marabô; exu-Caveira; exu-Sete Capas; exu-Tiriri; exu-Veludo; exu-TrancaRua; Pomba-Gira; Cigana e Dona Sete Saias.

As imprecisões são seu território, ele é o entre. O que confunde. O que escapa à classificação. Nenhuma narrativa é capaz de recuperar exu em sua totalidade. Existe totalidade? Ele é fragmentado, desterritorializado. Dá lugar a múltiplas verdades que não se coadunam com o uno e o idêntico a si mesmo. Questiona a universalização da "verdade", da centralidade discursiva tão comum ao pensamento ocidental. Embaralha as alternativas, coloca em tensão as particularidades e apresenta uma pluralidade de vozes em que o real é inesgotável.

Um mesmo nome exu percorre diversas passagens, se singulariza numa multiplicidade de momentos. Escapa do esquema binário, dando lugar aos jogos de força, a vetores que se ligam uns aos outros, simulando novas misturas. Exu expressa-se nos acontecimentos, nos eventos, nas singularidades, não tem uma estrutura definida. É rizomático:

O esquema rizomático não leva em conta genealogias (esquema arborescente) ou evolucionismos; pensar multiplicidades é saber 
que, ao invés de definições fechadas e de conceitos prévios, o que se tem são agenciamentos, conexões entre todos os lados, hibridações que mudam de acordo com os novos acontecimentos que se criam. (FERREIRA, 2008, p.34)

O que está em jogo aqui não é conceituar quem é exu, mas abrir caminhos para a compreensão dos eventos em que ele se faz presente, em suas singularidades, revelando nesse percurso, sempre contextual, a heterogeneidade de diferentes linhas que o compõem.

Eu já não caibo mais em mim. A muito que estou por vir. Você me inventa, mas não me veta, você me sente, mas, não me enxerga, você me usa mas não abusa, lambuza, come, fale, me reinvente na sua mente [...] Sou criador, sou criatura, eu vou explodir em mim. Eu sou o mundo. Mais um. Mais um dia, mais uma hora, mais um pensamento, mais um lamento, mais um filho, mais um sexo, mais um pai, mais um [...] Tá tudo muito caos, sempre esteve. Escuta. Esse é o som do mundo, essa harmonia gritando na esquina, gritando no arranha-céu. [...] Eu sou o infinito mais um. (Exu: a Boca do Universo ${ }^{14}$ apud FERNANDES, 2015, p.73)

Mergulhar em exu pressupõe se atentar para as realidades plurais em que ele está inserido, realidades que são da ordem da incompletude e da sinuosidade, que multiplica e diferencia exu(s) em múltiplas tonalidades. É ter a atenção sensível não para encontrar exu em sua totalidade, mas sim para seguir seus rastros nos processos e devires que o compõem, em continuo arranjo e rearranjo. Mergulho que será sempre inacabado, em via de fazer-se, posto que exu enrola e desenrola, se dobra e desdobra, implica e explica, complica.

\section{REFERÊNCIAS BIBLIOGRÁFICAS}

14 "Exu: a Boca do Universo" é uma peça teatral promovida pelo Núcleo de Teatro de Alagoinhas NATA. Tem direção de Fernanda Júlia, direção musical de Jarbas Bittencourt e coreografia de Zebrinha. 
AMADO, Jorge. Bahia de todos os santos: Guias de Ruas e Mistério. Rio de janeiro: Record, 1981.

ANJOS, José Carlos. A Filosofia Política da Religiosidade Afro-Brasileira como Patrimônio Cultural Africano. Debates do NER, Porto Alegre, ano 9, n.13, p. 77-96, jan/jun. 2008.

BASSI, Francesca; TAVARES, Fátima. Para além da eficácia simbólica: estudos em ritual, religião e saúde. Salvador: EDUFBA, 2013.

BASTIDE, Roger. As Religiões Africanas no Brasil: contribuição a uma sociologia das interpenetrações de civilizações. São Paulo: Enio Matheus Guazzelli\& Cia. Ltda, 1989.

CACCIATORE, Olga Gudolle. Dicionário de Cultos Afro-Brasileiros. Rio de Janeiro: Editora Forense Universitária, 1977.

CAPONE, Stefania. A busca da África no Brasil: tradição e poder no Brasil. Rio de Janeiro: Pallas/Contracapa, 2004.

COELHO, L; TRINDADE, L. Exu: O Homem e o Mito: estudos de Antropologia Psicológica. São Paulo: Terceira Margem, 2006.

DELEUZE, Gilles; GUATTARI, Felix. 1995. Mil platôs: capitalismo e esquizofrenia, vol. 1 [tradução de Aurélio Guerra e Célia Pinto Costa]. Rio de Janeiro: Ed. 34, 2012.

Mil Platôs: capitalismo e esquizofrenia, vol.4 [tradução de Suely Rolnik]. Rio de janeiro: Ed.34,

FERNANDES, Alexandre de Oliveira. Axé: apontamentos para uma a-tese sobre Exu que jamais (se) escreverá - Rio de Janeiro/Rio de Janeiro. 2015. 344 f. Tese (Doutorado em Ciência da Literatura) - Programa de Pós- Graduação em Ciência da Literatura, Universidade Federal do Rio de Janeiro, Rio de Janeiro, 2015.

FERREIRA, Flávia Turino. Rizoma: um método para as redes? Liinc em Revista, Rio de Janeiro, v.4, n.1, março, p. 28-40, 2008. 
GILROY, Paul. O Atlântico Negro: modernidade e dupla consciência. São Paulo: ditora 34, 2001.

GOLDMAN, Márcio. Formas do saber e Modos do Ser: observações sobre multiplicidade e ontologia no candomblé. Religião e Sociedade, Rio de Janeiro, v. 25, n. 2, p. $102-120,2005$.

Histórias, devires e fetiches das religiões afro-brasileiras: ensaio de simetrização antropológica. Análise social, Lisboa: Instituto de Ciências Sociais da Universidade de Lisboa, v. XLIV, p. 105-137. 2008

LODY, Raul Giovanni da Motta. O povo de santo: religião, história e cultura dos orixás, voduns, inquices e caboclos. Rio de Janeiro: Pallas, 1995.

PRANDI, Reginaldo. Exu, de mensageiro a diabo: Sincretismo católico e demonização do orixá Exu.Revista USP, São Paulo, 2001, n.5o, junho/agosto, p.4663.

RABELO, Miriam. Entre a Casa e a Roça: trajetórias de socialização no Candomblé de habitantes de bairros populares de Salvador. Revista Religião e Sociedade, Rio de Janeiro, 2008, n.1, v.28, p. 176-205.

RAMOS, Artur. As culturas negras no novo mundo. 3. ed. São Paulo: Nacional, 1979. (Coleção Brasiliana, 249).

RODRIGUES, Raimundo Nina. O Animismo Fetichista dos Negros Bahianos. Bahia: s/e, 1935 .

SANTOS, Juana Elbein. Os Nagô e a Morte. Editora Vozes, 1986.

SILVA, Vagner Gonçalves. Exu do Brasil: tropos de uma identidade afro-brasileira nos trópicos. Revista de Antropologia, São Paulo, USP,2012, n.2, v.55, p. 1085 - 1114. VERGER, Pierre. Notas sobre o culto aos Orixás e Voduns. São Paulo: Editora da Universidade de São Paulo, 2012. 
